\title{
O PARADIGMA DO MOVIMENTO RELATIVO DE FALHAS NA MODELAGEM FÍSICA ANALÓGICA
}

\author{
Caroline J. S. Gomes (*), André Danderfer Filho (*), \\ Silvia Carolina Braga $(* *)$ \& Maria Verônica Pessoa
}

\begin{abstract}
Scaled analogue fault-block models were constructed with homogenous sand packs to discuss the paradigm of their relative motion. In a first set of extensional experiments, we simulated hanging wall dislocation above a listric normal detachment as described in the literature and compared it to a footwall deformation experiment. An inverted extensional fault system was also constructed to analyze the effect of hanging wall and footwall deformation. Our models demonstrate that the active fault block partially controls the evolution of fault systems. In extensional domains, translation of the hanging wall produces clockwise rotation of antithetic faults, resulting in lower dip angles than those formed by activation of the footwall block. In the experiments involving extension and inversion, thrusts nucleate at the fault-flat by activation of the hanging wall-block, and at the faultramp-toe by activation of the footwall-block. Thus, in the footwall deformation model, ascension and thickening of the syn-rift deposits occur during the early stages of deformation.
\end{abstract}

Keywords: analogue modelling, extension, tectonic inversion, footwall dislocation, hanging wall dislocation.

\section{RESUMO}

\begin{abstract}
Em experimentos de areia foram simulados sistemas de falhas distensivos e de inversão tectônica positiva, com o objetivo de discutir o paradigma do movimento relativo de blocos de falhas. Os sistemas, que representam hemigrabens com falha de borda lístrica, foram simulados, em diferentes modelos, com translação do bloco do teto e do muro. Os experimentos demonstraram que o bloco móvel de uma falha normal lístrica influencia na arquitetura dos sistemas estruturais. Em uma bacia extensional, o ângulo de mergulho das falhas internas, antitéticas, é mais baixo quando o bloco do teto é móvel. Isto ocorre, porque o movimento progressivo do teto causa rotação horária destas falhas. Nos experimentos de inversão tectônica, o fechamento da bacia pelos diferentes blocos, do muro e do teto, causa a reativação do descolamento basal em dois domínios distintos, no início da rampa e ao longo de seu segmento horizontal, respectivamente. O fato conduz à nucleação de falhas de empurrão (e retroempurrão) em posições distintas. Assim, quando o bloco do muro é móvel, ascensão e espessamento do pacote sin-rifte ocorrem, sob baixa magnitude de deformação, no início do processo deformacional.
\end{abstract}

Palavras-chave: modelagem física, extensão, inversão tectônica, translação do bloco do muro e teto

\section{INTRODUÇÃO}

A Modelagem Física Analógica é uma ferramenta da Geologia Estrutural e Tectônica, na qual eventos e mecanismos deformacionais são simulados, com materiais analógicos apropriados, em escala. Constitui o método mais didático da tectônica experimental, principalmente quando os ensaios são efetuados em 'caixas de areia'. Tem como objetivo testar a aplicabilidade mecânica e cinemática de modelos tectônicos teóricos, ilustrar a evolução progressiva da deformação, em duas e três dimensões, indicar eventuais estruturas ainda não descobertas no terreno e estudar os mecanismos da deformação.

O presente estudo de modelagem física ilustra a evolução progressiva de domínios distensivos e de inversão tectônica, nos quais os movimentos de abertura e fechamento se processaram pela translação do bloco do muro (lapa; footwall) da falha mestra ao invés do bloco do teto (capa; hanging wall). Os experimentos físicos de bacias sedimentares descritos na literatura assumem o bloco do muro estático, isto é, inativo, de maneira que o bloco do teto é o único responsável por causar deformações. O arcabouço tectônico resultante tanto da fase de extensão como da inversão do teto são bem conhecidos (por ex. McClay 1990 e 1995). Um dos problemas da aplicação dessa premissa reside no fato de que, nem sempre o mecanismo motriz responsável pelas deformações na crosta terrestre se situa no segmento correspondente ao compartimento do teto. Inúmeros casos tem sido relatados ou são melhor interpretados, posicionando o foco das tensões no lado do bloco do muro (por exemplo, McClay et al., 1989; Butler, 1989; Hayward \& Graham, 1989). Neste caso, o teto deve sofrer deformação passiva, mediante acomodação por dobras e falhas associadas. 
Com base em tais considerações, o Grupo de Pesquisa em Modelagem Geológica de Bacias Sedimentares do Departamento de Geologia da Universidade Federal de Ouro Preto (Degeo/Ufop) iniciou um projeto, no qual enfatiza-se a modelagem frontal e oblíqua de sistemas tectônicos induzidos pela mobilidade do bloco do muro. Este projeto envolve questões filosóficas inerentes à formação de bacias e uma mudança de paradigma na montagem de experimentos especialmente os que abrangem regimes transtrativos e transpressivos. Neste sentido, conduz ao aperfeiçoamento dos aparatos experimentais.

De modo específico, este trabalho ilustra os primeiros resultados do projeto a partir de um exemplo simples, de extensão e inversão frontal. Nesses experimentos, os movimentos de abertura e fechamento se processaram primeiro, de forma convencional, pela translação do bloco do teto e depois pelo bloco do muro. Tais procedimentos tem por objetivo comparar os arcabouços tectônicos resultantes por mobilidade ativa dos blocos da capa e da lapa.

\section{AMODELAGEMFÍSICAANALÓGICA}

Os experimentos de modelagem física analógica deste projeto vem sendo conduzidos no Laboratório de Modelagem Tectônica do Degeo/Ufop. Os métodos obedecem aos preceitos da teoria da similaridade desenvolvida por Hubbert (1937), os quais permitem que a deformação seja reproduzida no laboratório através de caixas de experimentos de dimensões centimétricas. Nos presentes experimentos utilizou-se areia seca que rompe de acordo com o critério de Coulomb-Mohr, independe da taxa de deformação e possui baixa coesão (Vendeville et al. 1987; McClay \& Ellis 1987). Para a comparação da deformação rúptil entre o modelo simulado (em laboratório) e o original (da natureza) relacionam-se os parâmetros físicos, tensão $(\sigma)$ e comprimentos $(\lambda)$, na equação:

$$
\begin{aligned}
& \sigma_{\mathrm{r}}=(\delta)(\lambda)(\text { Hubbert 1937) } \\
& \text { onde } \\
& \sigma_{\mathrm{r}}=(\Delta \sigma)_{\text {modelo }} /(\Delta \sigma)_{\text {original }} \\
& \text { o que corresponde a (coesão) })_{\text {modelo }} /(\text { coesão })_{\text {original }} \text {, } \\
& \delta=(\text { densidade })_{\text {modelo }} /(\text { densidade })_{\text {original }} \\
& \mathrm{e} \\
& \lambda=(\text { comprimento })_{\text {modelo }} /(\text { distância })_{\text {original }}
\end{aligned}
$$

A equação (1) demonstra que, se no modelo, a distância entre dois pontos é diminuída por um fator de escala $=10^{-5}(1 \mathrm{~cm}=1 \mathrm{~km})$ é preciso reduzir o seu coeficiente de coesão $\mathrm{s}_{\mathrm{r}}$, também por $10^{-5}$ (ou 100.000 vezes) uma vez que, por se manter constante em qualquer distancia, a densidade dos materiais muito pouco influencia no resultado da equação. Uma redução de 100.000 vezes na coesão da rocha natural resulta para o material analógico, em uma coesão próxima a zero e este é o caso da areia seca (McClay \& Ellis 1987).
A areia de quartzo empregada no Laboratório de Modelagem Tectônica da Universidade Federal de Ouro Preto é peneirada na granulometria de $0,2 \mathrm{~mm}$ a 0,3 $\mathrm{mm}$, e tingida em diferentes cores para a visualização de camadas e estruturas. $\mathrm{O}$ ângulo de atrito interno da areia corresponde a $34^{\circ}$ (Gomes et al., 1998).

\section{MÉTODOEXPERIMENTAL}

Duas séries de experimentos foram montadas em caixas de acrílico, transparentes, com dimensões de 20 x 60 x $10 \mathrm{~cm}$ (largura x comprimento x altura), conforme representado na figura 1 . A falha mestra possui geometria lístrica com ângulo de emergência igual a $60^{\circ}$. Em todos os experimentos do presente estudo, o bloco do teto da falha foi simulado por um pacote de camadas de areia de diferentes cores, enquanto o bloco do muro foi representado por madeira. Este procedimento não permite, no entanto, que o bloco do muro participe da deformação, mas, por outro lado, como demonstram Gomes et al. (no prelo) (Fig.7, neste trabalho), não causa diferenças na arquitetura das estruturas do teto, durante a extensão.

A primeira série de modelos, constituída por dois experimentos, simulou uma etapa de deformação única, de extensão. Simulou-se o rifteamento, em um experimento com o bloco do teto da falha móvel (experimentos EXT-TM) e em outro, com o bloco do muro móvel (experimentos EXT-MM).

$\mathrm{Na}$ segunda série, também formada por dois experimentos, a deformação consistiu de duas etapas, uma de extensão e outra de inversão tectônica. Processaram-se as duas etapas de deformação da mesma forma como na primeira série, um experimento com o teto móvel (experimentos INV-TM) e outro, com o muro móvel (experimentos INV-MM). Nos modelos com o bloco do teto móvel, experimentos EXT-TM e INV$\mathrm{TM}$, introduziu-se uma folha de plástico sobre o bloco de madeira e o fundo da caixa, antes do início da deposição da areia. A porção horizontal da folha de plástico foi presa à parede frontal móvel, que, acoplado a um motor, causou a deformação, a uma velocidade constante de $2 \mathrm{~cm} / \mathrm{h}$. No experimento INV-TM, de inversão pelo bloco do teto, a folha de plástico foi puxada para fora do experimento antes da segunda etapa de deformação, sem causar danos ao modelo de areia. Os modelos com o muro móvel, experimentos EXTMM e INV-MM, foram desenvolvidos sem a utilização da folha de plástico (Fig. 1).

Em todos os experimentos o procedimento, durante a deformação, foi idêntico. À medida que a bacia se formava, ela era preenchida com finas camadas de areia de diferentes cores que permitiram o reconhecimento das estruturas sin-rifte. Ao final dos ensaios, os modelos foram molhados com água e, então, cortados na direção do transporte tectônico. Os experimentos foram repetidos várias vezes para a confirmação dos resultados. 


\section{DESCRIÇÃODOS MODELOS}

\section{I - Primeira série}

\section{Experimento Extensão com o Teto Móvel (EXT-TM)}

O modelo, de dimensões iniciais de 20,24 e $5 \mathrm{~cm}$ (largura, comprimento e altura), foi submetido à uma extensão total de $12 \mathrm{~cm}(50 \%)$. A figura 2 mostra três etapas do experimento EXT-TM, em intervalos correspondentes a $4 \mathrm{~cm}$ de extensão. No experimento formou-se um gráben assimétrico e um anticlinal de roll-over cuja curvatura aumenta com a magnitude da extensão. No bloco do teto aparece um crestal-collapse graben logo no início da deformação, com falhas planas a levemente curvas, convexas para baixo (Fig. 2a). Com a deformação progressiva (Fig. 2b) as falhas sofrem rotação horária (falhas 1, 3 e 5) ou anti-horária (falhas 4 e 2), diminuindo o seu ângulo de mergulho, e cresce a curvatura de suas superfícies. A extensão progressiva causa a formação de novas falhas normais (falhas 6, 7 e 8)(Fig. 2c), também curvas, no interior da bacia.

\section{Experimento Extensão com o Muro Móvel (EXT-MM)}

No experimento EXT-MM (Fig. 3), de comprimento inicial menor do que no modelo anterior, de 20, 16 e $5 \mathrm{~cm}$ (largura, comprimento e altura), a deformação total foi de $9 \mathrm{~cm}(56 \%)$. A bacia assimétrica, gerada pela translação do bloco do muro, também mostra falhas levemente curvas. Neste modelo, no entanto, as falhas antitéticas (falhas 1, 2 e 3), que cortam as seqüências pré- e sin-rifte, sempre com alto ângulo de mergulho, possuem convexidade voltada para cima. É interessante notar que estas falhas não rotacionam com a deformação progressiva. Falhas sintéticas só começam a aparecer após $6 \mathrm{~cm}$ (37.5\%) de extensão (Fig. 3B). Estas, se diferenciam de estrutura similar, no modelo anterior, pelo menor rejeito de suas falhas, mal caracterizando um crestal-collapse graben.

\section{II - Segunda série}

\section{Experimento Extensão e Inversão com o Teto Móvel (INV-TM)}

A primeira etapa de deformação do experimento INV-TM, de $12 \mathrm{~cm}$ de extensão, processou-se da mesma forma como no modelo EXT-TM, e estruturas similares se desenvolveram (comparar as figuras $4 \mathrm{~A}$ e $2 \mathrm{~B}$, ambas com 33\% de deformação). As figuras 4B e C apresentam os empurrões e retroempurrões geradas durante a segunda etapa, de inversão tectônica, com $8 \mathrm{~cm}(25 \%)$ e de $12 \mathrm{~cm}(37,5 \%)$ de encurtamento, respectivamente. A figura 4B mostra que, após $25 \%$ de encurtamento, o segmento em rampa do empurrão E1 corta as falhas normais antitéticas 1, 3, 5 e 6, preexistentes. Com a deformação progressiva dois novos empurrões (E2 e E3) se formam no antepaís (Fig. 4C) causando o desaparecimento das falhas normais sintéticas, 7 e 8 .

Em função do alto ângulo de emergência e da forte curvatura do descolamento normal (D), esta falha não sofre reativação até o encurtamento máximo de 37,5\% (final do experimento). Toda a deformação é acomodada sobre empurrões e retroempurrões que caracterizam uma estrutura em pop-up. A seqüência de desenvolvimento de empurrões e retroempurrões é sempre do tipo colapso da lapa (em direção ao bloco do muro, no caso dos empurrões, e em direção ao pós-país, no caso dos retroempurrões).

Observa-se que o retroempurrão mais antigo, R1, sobe ao longo do empurrão mais novo, E1, e, este, por sua vez, ascende sobre o retroempurrão mais novo (R2), não havendo truncamento entre os planos.

\section{Experimento Extensão e Inversão com o Muro Móvel (INV-MM)}

A extensão de $12 \mathrm{~cm}(50 \%)$, da primeira etapa de deformação, gerou neste modelo oito falhas normais antitéticas, de alto ângulo de mergulho, e duas falhas sintéticas(Fig. 5A). A inversão tectônica, processada pelo bloco do muro mostra, após $6 \mathrm{~cm}$ de encurtamento (18,75\%) (Fig. 5B), reativação do descolamento lístrico (D) e aumento na curvatura do anticlinal de roll-over, que é forçado a subir a rampa. Além disto, observa-se a formação de uma falha de empurrão (E1) no contato das seqüências sin- e pré-rifte. A deformação progressiva, até $12 \mathrm{~cm}$ de compressão total $(37,5 \%)$, produz novos cavalgamentos sempre acompanhados por retrocavalgamentos. Estas estruturas truncam as falhas normais mais antigas, deslocando algumas e obliterando outras.

É interessante notar que, neste modelo, diferente do experimento anterior, os retroempurrões mais novos (R2 e R3, figura 5C), se propagam no mesmo sentido que os empurrões, em direção ao antepaís.

O conjunto de estruturas compressivas gerou no experimento INV-MM forte ascensão das seqüências pré- e sin-rifte. 
A Modelo EXT-TM
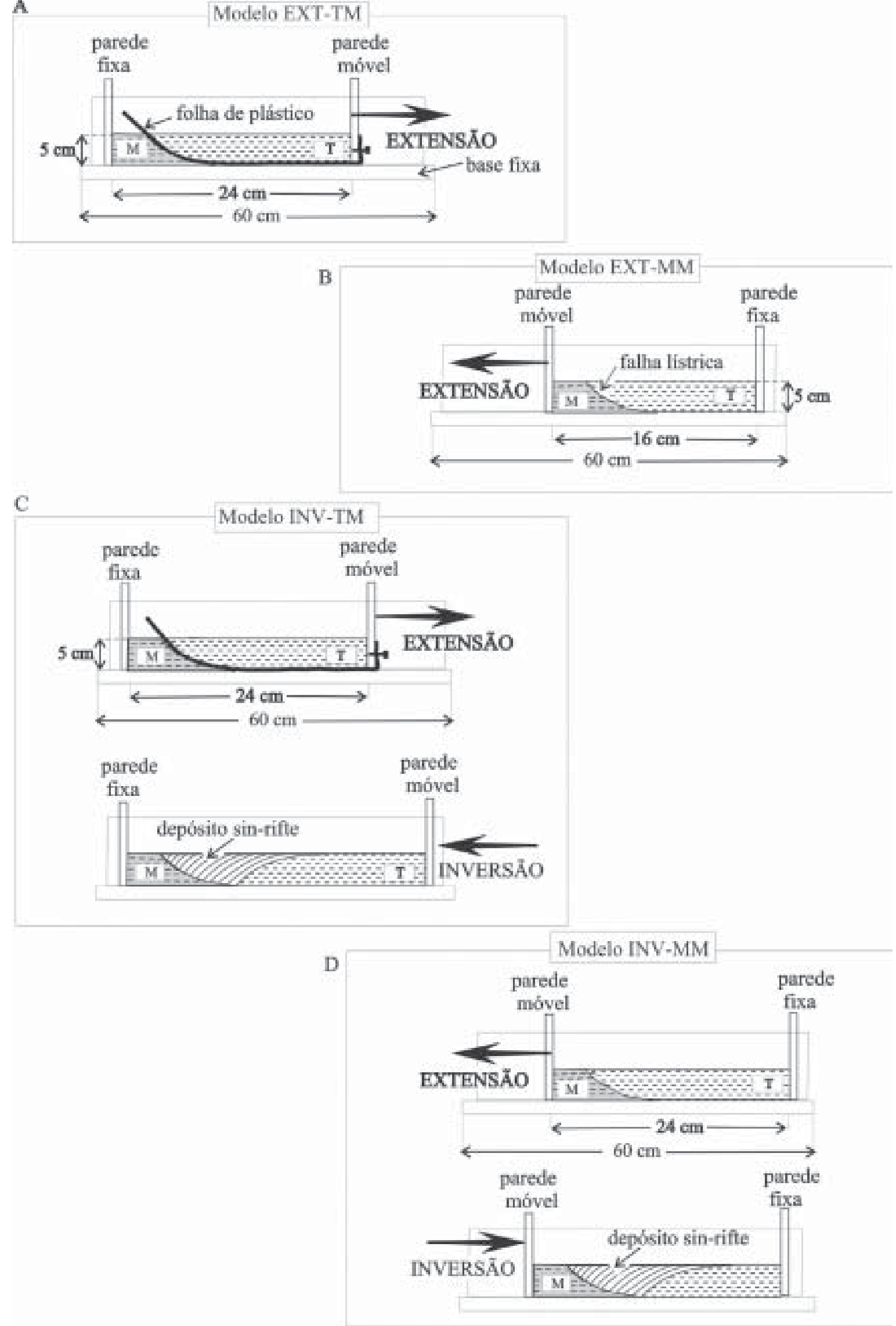

Figura 1. Desenho esquemático das caixas dos quatro modelos com as respectivas condições de contorno: (A) Experimento Extensão com o Teto Móvel (EXT-TM); (B) Experimento Extensão com o Muro Móvel; (EXT$M M)(C)$ Experimento Extensão e Inversão com o Teto Móvel (INV-TM); (D) Experimento Extensão e Inversão com o Muro Móvel (INV-MM); as letras T e M representam os blocos do teto e do muro, respectivamente. 

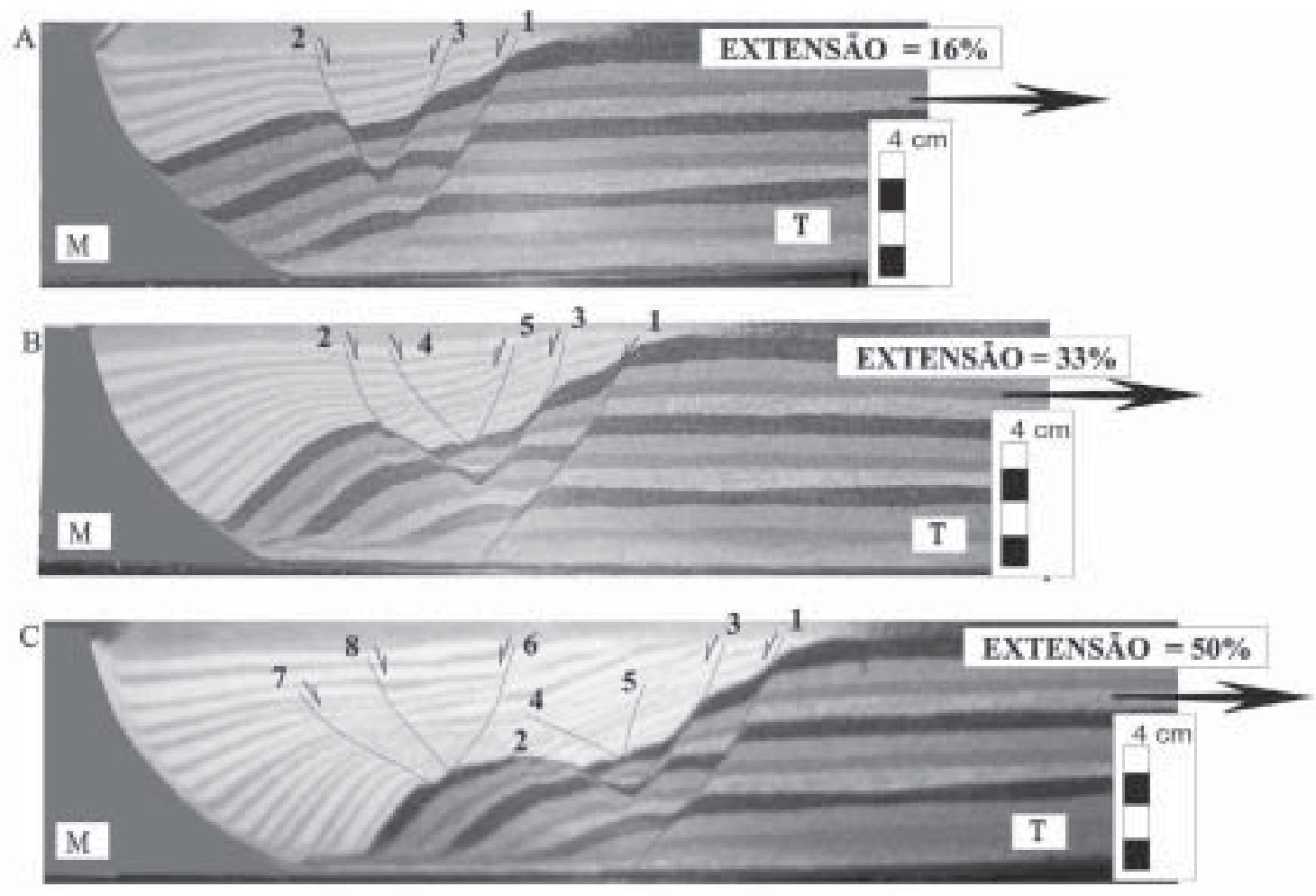

Figura 2. Fotografias mostrando o resultado de três etapas do experimento 'Extensão com o Teto Móvel' (EXT-TM), (A) após $4 \mathrm{~cm}$ de extensão (16\%); (B) após $8 \mathrm{~cm}$ (33\%); e (C) após $12 \mathrm{~cm}(50 \%)$. As letras $T$ e M representam os blocos do teto e do muro (do pré-rifte), respectivamente, e a seta o sentido do movimento. Os números indicam a ordem de formação das falhas. O pacote de areia mais claro, em duas tonalidades de cinza, simula o depósito sin-rifte.
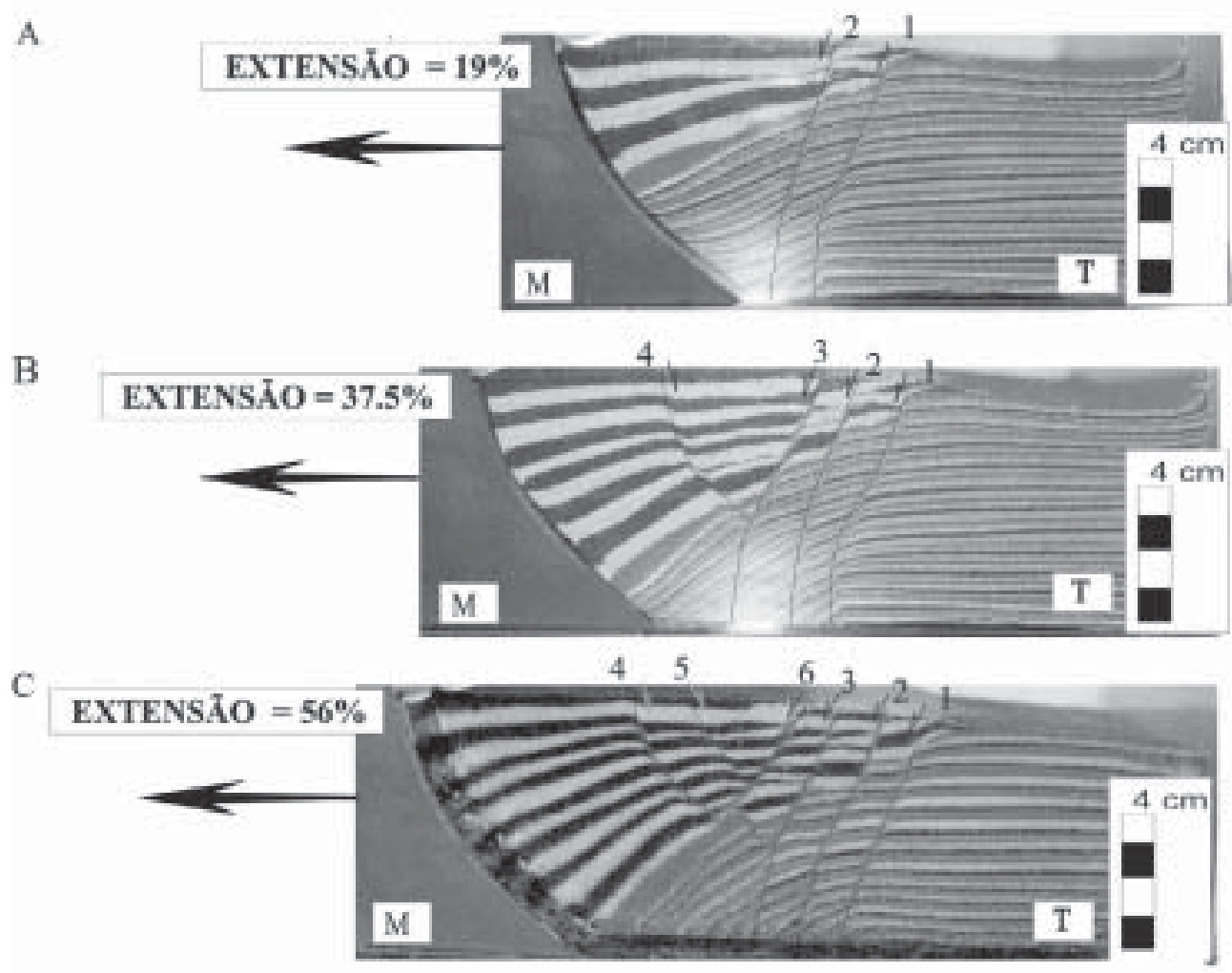

Figura 3. Fotografias mostrando o resultado de três etapas do experimento 'Extensão com o Muro Móvel' (EXT-MM), (A) após $3 \mathrm{~cm}$ de extensão (19\%); (B) após $6 \mathrm{~cm}$ (37.5\%); e (C) após $9 \mathrm{~cm}$ (56\%). As letras Te M representam os blocos do teto e do muro (do pré-rifte), respectivamente, e a seta o sentido do movimento. Os números indicam a ordem de formação das falhas. O pacote de areia, de camadas mais espessas e escuras, simula o depósito sin-rifte. 

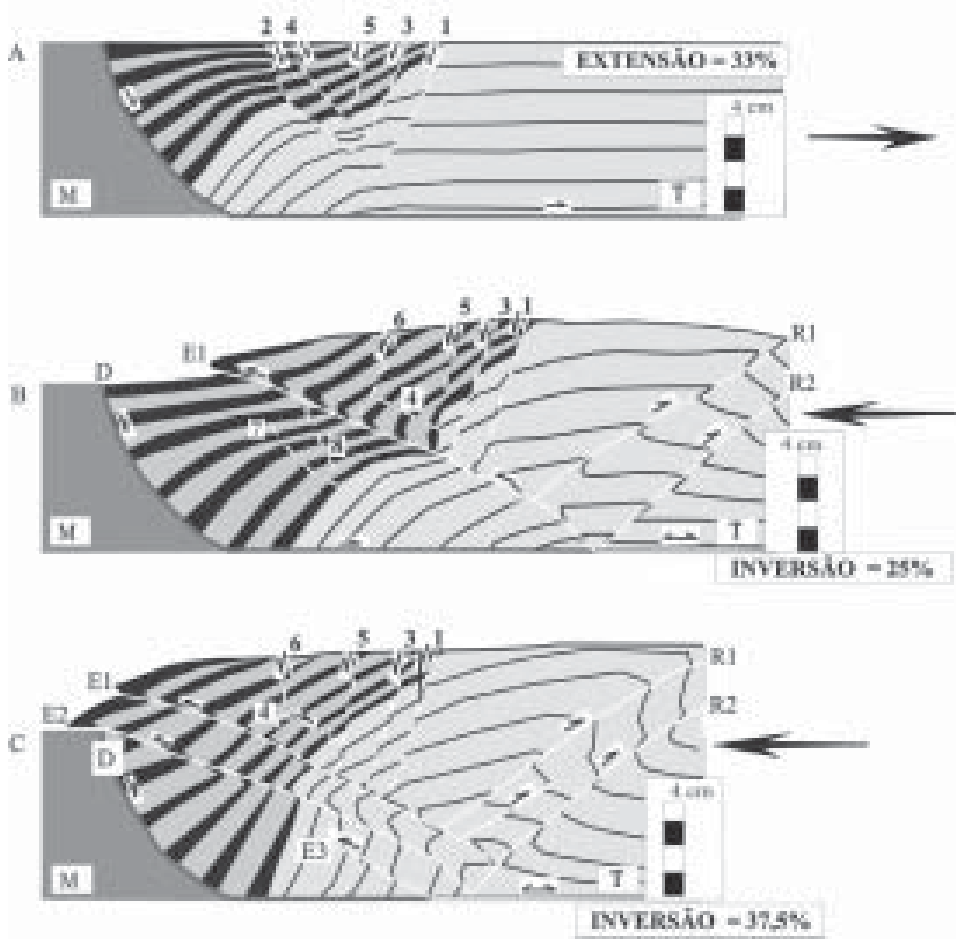

Figura 4. Desenho do experimento 'Inversão com o Teto Móvel' (INV-TM); (A) após $8 \mathrm{~cm}$ de extensão (33\%) da primeira etapa de deformação (não corresponde à extensão total); (B) após $8 \mathrm{~cm}$ de encurtamento

(25\%), da segunda etapa de deformação, de inversão tectônica; e (C) após $12 \mathrm{~cm}(37,5 \%)$ de encurtamento. As letras T e M representam os blocos do teto e do muro, respectivamente, e a seta o sentido do movimento. Os números indicam a ordem de formação das falhas normais; E1, E2, E3 e R1, R2 a ordem de formação dos empurrões e retroempurrões, respectivamente. D indica o descolamento basal.
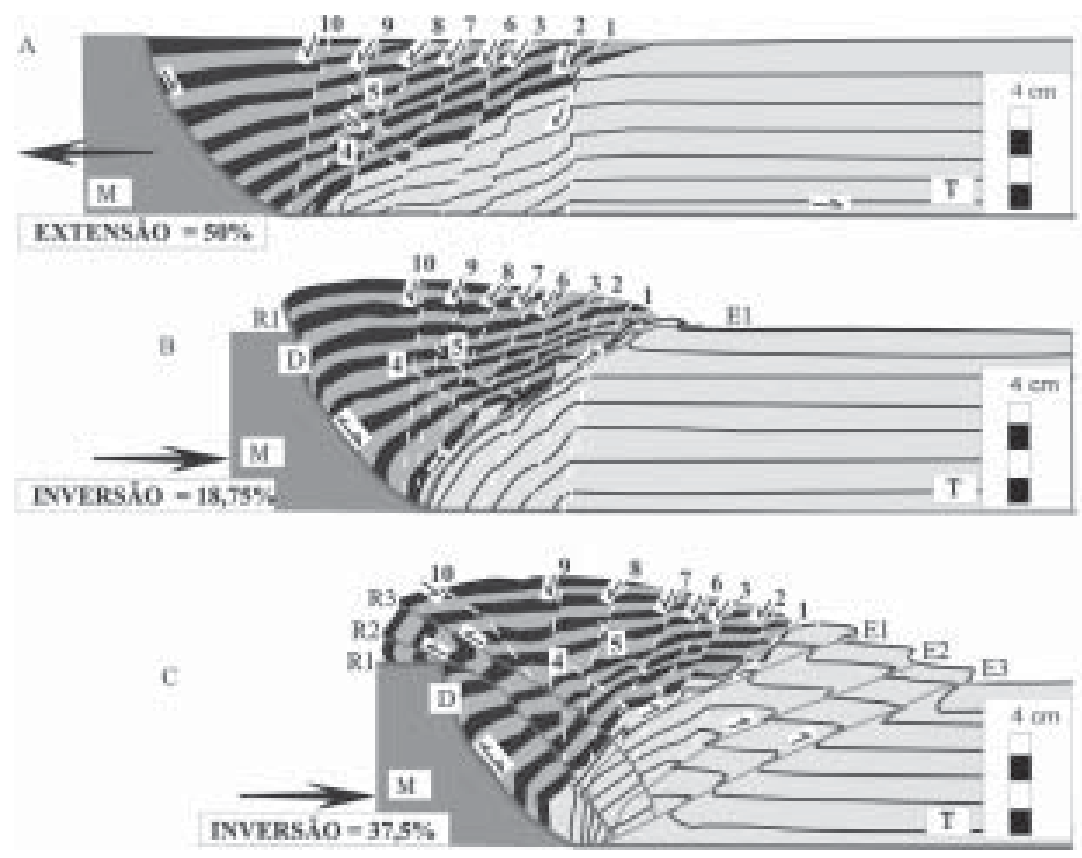

Figura 5. Desenho do experimento 'Inversão com o Muro Móvel' (INV-MM);

(A) após $12 \mathrm{~cm}$ de extensão (50\%) da primeira etapa de deformação;

(B) após $6 \mathrm{~cm}$ de encurtamento $(18,75 \%)$, da segunda etapa de deformação, de inversão tectônica; e (C) após $12 \mathrm{~cm}(37,5 \%)$ de encurtamento total.

As letras T e M representam os blocos do teto e do muro, respectivamente, e a seta o sentido do movimento.

Os números indicam a ordem de formação das falhas normais;

E1, E2, E3 e R1, R2, R3 a ordem de formação dos empurrões e retroempurrões, respectivamente.

$D$ indica o descolamento basal. 


\section{DISCUSSÃO}

\section{Comparação entre os modelos físicos}

A comparação entre os dois modelos que simularam a extensão, EXT-TM e EXT-MM (Figs. 2 e 3), mostra que a arquitetura dos hemigrábens gerados não é igual. Os modelos se distinguem pelo ângulo de mergulho das falhas internas, que é menor no experimento com o bloco do teto móvel (EXT-TM). Neste modelo, a deformação progressiva causa rotação das falhas antitéticas e sintéticas, em função de um processo de estiramento do bloco do teto, por acomodação interna do material analógico, durante a translação. No modelo EXT-MM, a abertura da bacia é causada pelo bloco do muro, de maneira que o teto permanece imóvel sofrendo apenas ruptura, sem rotação das falhas internas.

A principal diferença entre os experimentos de inversão tectônica, modelos INV-TM e INV-MM, reside na posição do leading branch-line, linha que delimita o domínio em ascensão (McClay 1992) e representa a interseção entre empurrões e retroempurrões. Considerando-se que o leading branchline se posiciona à frente do backstop, era previsível que tal fato sucedesse. Em conseqüência, o espessamento do pacote sin- e pré-rifte, ocorreu, nos modelos, em domínios distintos: à frente do bloco do muro e à frente do backstop de madeira, modelos INVMM e INV-TM, respectivamente (Figs.4 e 5).

No modelo INV-MM, o bloco do muro do descolamento basal assume o papel de um indenter. Bonini et al. (1999) mostram que um pacote de areia se deforma com vergência contrária ao sentido da compressão, quando a face frontal do indenter possui ângulo de inclinação $<45^{\circ}$. Em presentes experimentos, a falha lístrica possui, em profundidade, baixo ângulo de mergulho que cresce até emergir com ângulo próximo a $90^{\circ}$. Este fato explica, no modelo INV-MM, a reativação do segmento curvo do descolamento basal no início da deformação. O movimento reverso cessa à medida que o ângulo de mergulho do descolamento basal cresce e dificulta a ascensão do material analógico. Formam-se, então, sucessivos empurrões e retroempurrões. Resulta um relevo estrutural assimétrico com cotas mais altas nas proximidades do indenter.

A constatação acima, de que a principal diferença entre os modelos de inversão tectônica, INV-TM e INVMM, processados sob baixa magnitude de deformação, reside na posição do leading branch-line, permite sugerir que, com a deformação progressiva, esta diferença diminua. Assim, é possível assumir que uma alta magnitude de deformação, no fechamento da bacia (encurtamento $>37,5 \%$ ), produza um inventário estrutural de características similares para movimentos pelos blocos do muro e do teto.

\section{Comparação com modelos físicos da literatura}

A extensão simulada em presente trabalho, com translação pelo bloco do teto, modelo EXT-TM, mostra as mesmas feições descritas por McClay (1990), em modelos de areia. Nos experimentos do autor, a maior magnitude de deformação (até 100\%) torna mais evidente a rotação das falhas durante a deformação progressiva, que nos presentes modelos.

Os modelos experimentais de inversão positiva, clássicos, realizados por McClay (1989), com a translação do bloco do teto, mostram resultados um pouco diferentes dos aqui apresentados. Naqueles experimentos ocorre, durante a inversão, reativação não apenas do descolamento basal, mas também das falhas sintéticas e antitéticas, do crestal collapse graben (Fig. 6). McClay (1989) simulou a inversão tectônica com um pacote de camadas de areia intercaladas com horizontes finos de cristais de mica. A mica, no pacote de areia, além de induzir ao deslizamento entre as camadas, causa uma movimentação maior do bloco do teto sobre o descolamento basal. Diferente do que nos presentes modelos, naqueles, o teto, ao se movimentar ao longo do segmento horizontal da falha normal, só encontra resistência ao deslizamento no início da rampa. Neste domínio, causa a reativação das estruturas presentes e a formação de novas falhas.

Gomes et al. (no prelo) realizaram experimentos de extensão e inversão tectônica, nos quais ambos os blocos da falha normal mestra foram simulados com areia seca. A arquitetura das bacias distensivas não difere daquelas geradas por McClay \& Ellis (1989), com o muro rígido. Os modelos de inversão tectônica foram gerados por meio de extensão pelo bloco do teto e inversão pelo bloco do muro. Apesar desta diferença em relação aos presentes modelos, a comparação dos resultados é possível e a figura 7 mostra as estruturas produzidas. Neste modelo, empurrões e retroempurrões se desenvolvem junto ao bloco do muro à semelhança do que ocorre no modelo INV-MM. Na figura 7 observase, ainda, que os retroempurrões se desenvolveram como esperado no sentido descendente, diferente do que aconteceu em presentes experimentos. $\mathrm{O}$ fato demonstra que, no modelo INV-MM, a formação dos retroempurrões com propagação em direção ao antepaís decorre das características mecânicas do bloco do muro, que é rígido. 


\section{A- Inversẫo de uma falha listrica simples}

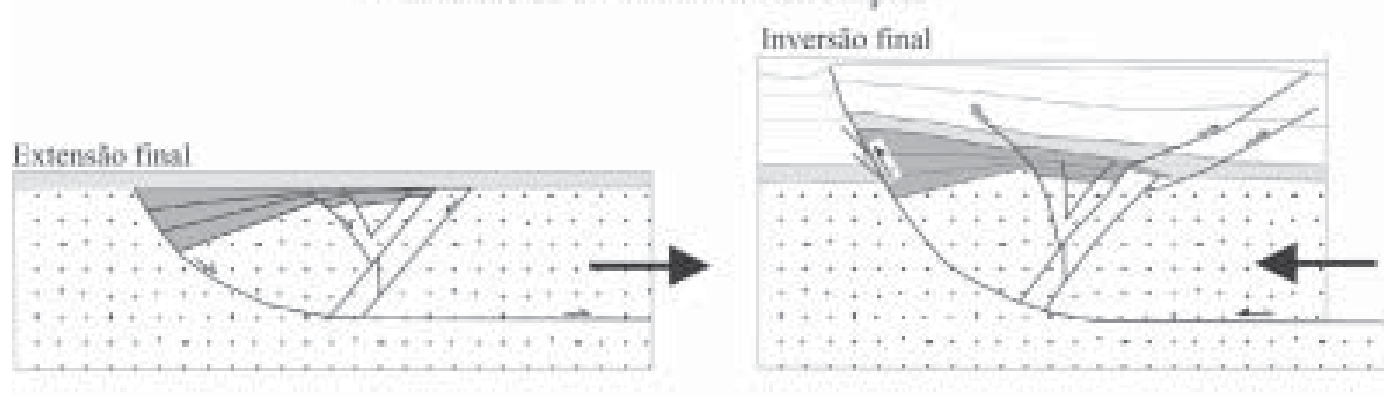

B- Inversào de uma fallha planar simples

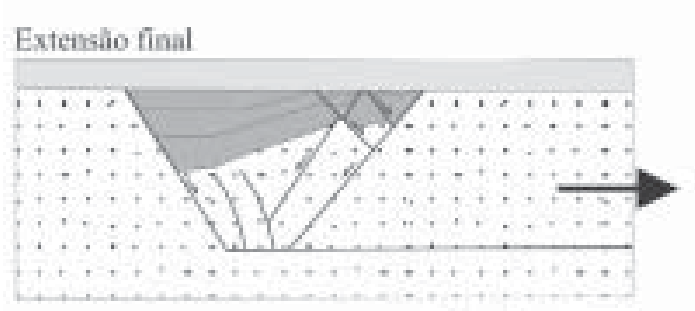

Sin-rifte Pré-rifte

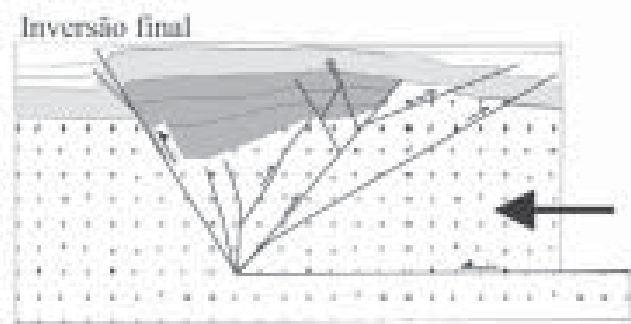

Sin-inversåo

Pós-rifte

Figura 6. Modelos sinópticos da inversão de falhas normais (A) lístrica e (B) plana (modificado de McClay, 1989).
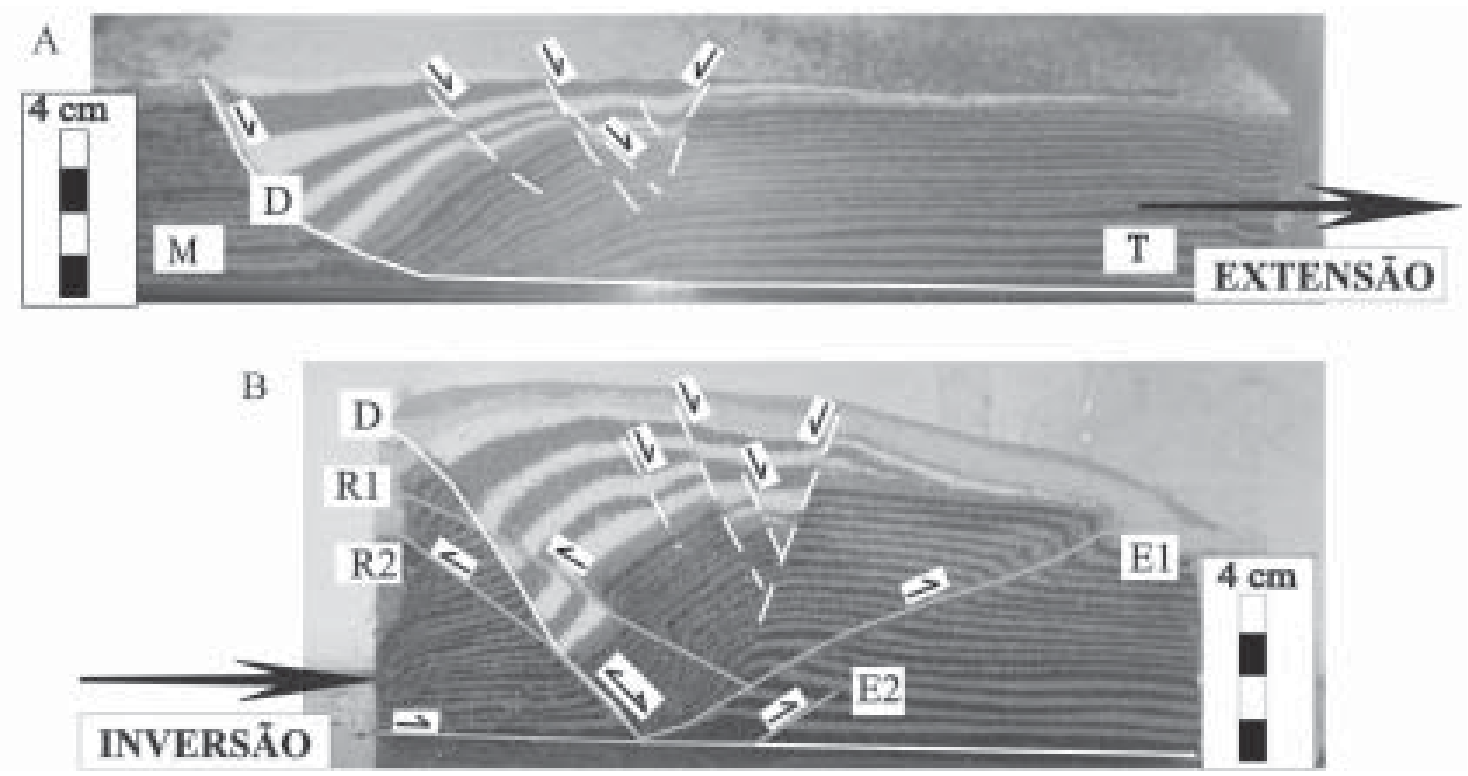

Figura 7. Fotografias mostrando o resultado de um experimento de inversão tectônica, com ambos os blocos da falha lístrica compostos de areia (modificado de Gomes et al. (no prelo)). (A) Extensão e (B) Inversão positiva. As letras $T$ e $M$ representam os blocos do teto e do muro, respectivamente, e a seta o sentido do movimento. E1, E2, e R1, R2 a ordem de formação dos empurrões e retroempurrões, respectivamente.

\section{Os modelos físicos e o protótipo}

Inexistem, na natureza, exemplos inequívocos de bacias abertas mediante movimentação absoluta do bloco do muro, porém isso não implica na impossibilidade de serem geradas falhas por esse mecanismo; que é particularmente comum em regimes transtrativos Por outro lado, encontram-se algumas descrições na literatura sugerindo o fechamento da bacia pelo movimento do bloco do muro da falha mestra (por exemplo, McClay et al., 1989; Butler, 1989; Hayward \& Graham, 1989; Knott et al., 1995; Danderfer, 2000; Gomes et al.(no prelo)).

Uma interpretação recente e alternativa para a inversão tectônica do setor setentrional da Serra do Espinhaço, posicionado na porção norte do Cráton do 
São Francisco, foi apresentada por Danderfer \& Dardenne (2001). Nela os autores sugerem que os processos que operaram na faixa Brasília foram responsáveis pela formação e inversão tectônica da bacia Santo Onofre, durante o Neoproterozóico - um hemigráben intracratônico com falha de borda mergulhando para leste (falha de Santo Onofre); neste contexto o segmento crustal situado a oeste dessa falha corresponderia ao bloco do muro, portanto ativo no processo deformacional do teto.

Uma modelagem física dessa hipótese terá que obedecer às condições de contorno observadas no presente trabalho. Para tanto, novos experimentos vem sendo desenvolvidos na tentativa de simular com maior profundidade os efeitos transtrativos e transpressivos que acompanharam a formação e a inversão da bacia Santo Onofre. Nos próximos experimentos tentar-se-á dar ênfase à obliqüidade dos movimentos visando simular melhor o arcabouço tectônico do Espinhaço Setentrional.

\section{CONCLUSÕES}

Os modelos demonstram que, ao contrário do que preconiza a teoria do falhamento, as características da deformação e a arquitetura das estruturas depende do movimento absoluto.

As bacias distensivas geradas nos experimentos pela translação do bloco do muro exibem falhas antitéticas com ângulo de mergulho mais elevado do que respectivas falhas em bacias abertas pela movimentação do bloco do teto.

Nos ensaios de inversão tectônica, por movimentação do bloco do muro, observa-se uma ascensão mais pronunciada dos domínios compartimentais pré- e sinrifte que nos experimentos por movimentação do bloco do teto. Isto acontece porque o bloco do muro atua, na inversão, como um indenter.

A análise dos experimentos de inversão tectônica permite sugerir que, sob alta magnitude de deformação (>>37,5\%, aqui simulados), a deformação progressiva produza um estilo deformacional similar para ambos os blocos em movimento.

\section{AGRADECIMENTOS}

Os autores expressam os seus agradecimentos à FAPEMIG, pelo auxílio financeiro (processo CRA 166/99) que tornou possível a realização deste trabalho.

\section{REFERÊNCIAS BIBLIOGRÁFICAS}

Bonini, M., Sokoutis, D., Talbot, C. J., Boccaletti, M. 1999. Indenter growth in analogue models of Alpine-type deformation. Tectonics, 18:119-128.

Butler, R.W.H., 1989. The influence of pre-existing basin structure on thrust system evolution in the Western Alps. In Cooper, M.A. \& Williams, G.D. (eds.) Inversion Tectonics Geological Society Special Publication 44:105-122.

Danderfer Filho, A. 2000. Geologia Sedimentar e Evolução Tectônica do Espinhaço Setentrional. Instituto de Geociências, Universidade de Brasília, Brasília, Tese de Doutoramento, 498p.

Danderfer Filho, A. \& Dardenne, M. A. 2001. Inversão tectônica da bacia Espinhaço ao longo da faixa ocidental do corredor de deformação do Paramirim, norte do cráton do São Francisco. In: Simpósio Nacional de Estudos Tectônicos, 8, Recife, 141-144.

Gomes, C.J.S., Vieira, J.F., Seabra Gomes, A.A., 1998. O ângulo de atrito interno da areia e de misturas de areia. In: Congresso Brasileiro de Geologia, 40, Salvador, 410-411.

Gomes, C.J.S., Ribeiro, V.E., Martins Neto, M. The southern Serra do Espinhaço Structure, positive inversion of a former footwall block: insights from experimental modelling. Journal Structure Geology (no prelo).

Hayward, A B., Graham,R.H., 1989. Some geometrical characteristics of inversion. In Cooper, M.A. \& Williams, G.D. (eds.) Inversion Tectonics, Geological Society Special Publication 44:17-39.

Hubbert, M.K., 1937. Theory of scale models as applied to the study of geological structures. Geological Society of America Bulletin 48:1459-1520.

Knott, S.D., Beach, A., Welbon, A.I., Brockbank, P.J., 1995. Basin Inversion in the Gulf of Suez: Implications for exploration and development in failed rifts. In Buchanan, J.G. \& Buchanan, P.G. (eds.), Basin Inversion, Geological Society Special Publication 88:59-81.

McClay, K.R., Ellis, P.G., 1987. Analogue models of extensional fault geometry's. In Coward, M.P., Dewey, J.F., Hancock, P.L. (eds.), Continental Extensional Tectonics, Geological Society Special Publication 28:109-125.

McClay, K.R., 1989. Analogue models of inversion tectonics. In Cooper, M.A. \& Williams, G.D. (eds.), Inversion Tectonics, Geological Society Special Publication 44: 41-59.

McClay, K.R., Insley, M.W., Anderton, R., 1989. Inversion of the Kechika Trough, Northeastern British Colombia, Canada. In Cooper, M.A. \& Williams, G.D. (eds.), Inversion Tectonics, Geological Society Special Publication 44:235-257.

McClay, K.R. 1990. Physical models of structural styles during extension. In Tankard \& Balkwill (eds.), Extensional Tectonics and Stratigraphy of the North Atlantic Margins, American Association of Petroleum Geologists, 46:95 - 110.

McClay, K.R., Buchanan, P.G. 1992. Thrust faults in inverted extensional basins. In McClay (ed.), Thrust Tectonics, Chapman \& Hall, London, 93-104.

McClay, K. R. 1992. Glossary of thrust tectonics. In McClay (ed.), Thrust Tectonics, Chapman \& Hall, London, 419433.

McClay, K.R. 1995. The geometries and kinematics of inverted systems: a review of analogue model studies. In Buchanan J.G. \& Buchanan, P.G. (eds.), Basin Inversion, Geological Society Special Publication 88:97-118.

Keller, J.V.A., McClay, K.R. 1995. 3D sandbox models of positive inversion. In Buchanan, J.G. \& Buchanan, P.G. (eds.), Basin Inversion, Geological Society Special Publication 88: 137146.

Vendeville, B., Cobbold, P.R., Davy, P., Brun, J.P., Choukroune, P., 1987. Physical models of extensional tectonics at various scales. In Coward, M.P., Dewey, J.F., Hancock (eds.), Continental Extensional Tectonics, Geological Society Special Publication 28:95-107. 